\title{
BMJ Open Sociodemographic and psychological determinants of influenza vaccine intention among recipients of autologous and allogeneic haematopoietic stem cell transplant: a cross-sectional survey of UK transplant recipients using a modified health belief model
}

\begin{abstract}
Paul D E Miller, ${ }^{1}$ Alice S Forster, ${ }^{2}$ Thushan I de Silva, ${ }^{3}$ Hayley Leonard, Chloe Anthias, ${ }^{1,4}$ Michaela Mayhew, ${ }^{5}$ Matthias Klammer, ${ }^{5}$ Susan Paskar, ${ }^{6}$ Erin Hurst, ${ }^{6}$ Karl Peggs, ${ }^{7}$ Alejandro Madrigal, ${ }^{1}$ John A Snowden ${ }^{8}$
\end{abstract}

To cite: Miller PDE, Forster AS, de Silva TI, et al. Sociodemographic and psychological determinants of influenza vaccine intention among recipients of autologous and allogeneic haematopoietic stem cell transplant: a crosssectional survey of UK transplant recipients using a modified health belief model. BMJ Open 2018;8:e021222. doi:10.1136/ bmjopen-2017-021222

- Prepublication history for this paper is available online. To view these files, please visit the journal online (http://dx.doi org/10.1136/bmjopen-2017021222).

Received 29 December 2017 Revised 29 April 2018 Accepted 30 May 2018

Check for updates

(C) Author(s) (or their employer(s)) 2018. Re-use permitted under CC BY-NC. No commercial re-use. See rights and permissions. Published by BMJ.

For numbered affiliations see end of article.

Correspondence to

Dr Paul D E Miller;

pauldemiller@doctors.org.uk

\section{ABSTRACT}

Objectives Studies exploring vaccination rates among haematopoietic stem cell transplant (HSCT) recipients have focused on physician factors that limit uptake. Understanding the patient factors that determine vaccination intention is crucial to delivering a successful vaccination programme. Using a modified health belief model (mHBM), we conducted a cross-sectional survey with the objective of exploring the sociodemographic and psychological factors that determined autologous and allogeneic HSCT recipients' intention to receive the seasonal inactivated influenza vaccine (SIIV) during the 2015-2016 influenza season.

Setting The setting of our study was three tertiary level, UK National Health Service (NHS) autologous and allogeneic HSCT centres.

Participants Eligible patients were aged 16 years or over and recipients of autologous or allogeneic HSCT for any disease indication, with no absolute contraindication to receiving the SIIV during the next influenza season, and having not received the SIIV since transplant. 93 participants from 3 UK NHS HSCT centres completed an anonymous study-specific questionnaire. $78.5 \%$ were recipients of allogeneic and $21.5 \%$ autologous HSCT. Results $23.7 \%$ of participants expressed low intent to receive the SIIV. Patients aged over 65 (OR $0.02,95 \% \mathrm{Cl}$ 0.01 to $0.57, p=0.02$ ) and those who had not received the SIIV prior to HSCT (OR $0.04,95 \% \mathrm{Cl} 0.02$ to $0.56, p=0.02$ ) were less likely to have high intent. A multivariate logistic regression model incorporating constructs of the $\mathrm{mHBM}$ was statistically significant $(p<0.001)$ and explained $74.7 \%$ of variation in SIIV intention. More patients felt that a recommendation from their HSCT team than their general practitioner would prompt them to receive the SIIV, and this was most pronounced in those who had low intent.

Conclusions The mHBM may provide a useful structure for addressing low vaccine intent among HSCT recipients
Strengths and limitations of this study

The study questionnaire was based on the established theoretical framework of the health belief model, and questions were specific with regard to vaccine and 2015-2016 season.

- Participants from three geographically dispersed study sites completed anonymous questionnaires

- The study explored intention to receive the inactivated influenza vaccine during the 2015-2016 influenza season. Uptake was not assessed and may differ from intention rates.

- The number of enrolled participants expressing low vaccination intent was small at $22(23.7 \%)$ and this may bias our data.

- The study did not include a qualitative component and there may be additional determinants of influenza vaccine intention not captured here.

and further interventional studies are warranted. We would encourage HSCT and general practitioners to discuss SIIV intention as a routine part of care.

\section{INTRODUCTION}

Innate and adaptive immune responses are impaired for months to years following autologous and allogeneic haematopoietic stem cell transplant (HSCT). Immune impairment following autologous HSCT is secondary to the administration of immunosuppressive conditioning regimens. In the setting of allogeneic HSCT, chronic graft versus host disease (GvHD) may also contribute to immune impairment and dysfunction through thymic 
atrophy $^{12}$ and functional hyposplenism, ${ }^{3}$ and the mainstay of GvHD treatment is immunosuppressive therapy. Infection is therefore an important complication of both autologous and allogeneic HSCT, and recipients are at high risk of morbidity and mortality from influenza viruses. ${ }^{4-6}$ Guidelines recommend that the seasonal inactivated influenza vaccine (SIIV) is administered annually starting 4-6 months post-HSCT, ${ }^{78}$ including patients with GvHD. ${ }^{9}$ While the SIIV is recommended by $96 \%$ of UK National Health Service allogeneic HSCT programmes, ${ }^{8}$ uptake rates of only $60 \%-70 \%$ in the first 2 years postHSCT have been reported among UK HSCT recipients. ${ }^{10} 11$ The majority of UK allogeneic HSCT recipients are referred to their general practitioner (GP) with only $8 \%$ of UK adult allogeneic HSCT programmes offering vaccination services. SIIV efficacy of $65.4 \%-80 \%$ has been reported in HSCT recipients, although in small cohorts. ${ }^{12}{ }^{13}$ In both the UK and USA, physicians' familiarity with current guidelines, and perception of GvHD as a contraindication to vaccination have been identified as factors limiting vaccine uptake rates. ${ }^{1011}{ }^{14}$ No studies to date have explored the patient factors that influence SIIV hesitancy or intention in an HSCT recipient population.

The health belief model (HBM) is a widely used framework for investigating psychosocial determinants of health behaviours ${ }^{15}$ and is recognised as an important predictor of influenza vaccination uptake. ${ }^{16}$ The HBM proposes that an individual's engagement in a specific preventative health behaviour is predicated on the following constructs: (1) perceived susceptibility to the illness, (2) perceived likelihood of contracting the illness, (3) perceived seriousness of the illness, (4) perceived barriers to engaging in the health behaviour, (5) perceived benefits of the health behaviour, (6) cues to engage in the health behaviour such as advice from a healthcare practitioner and (7) self-efficacy or the individual's perception of their capability to engage or succeed in the behaviour. Additional emotional constructs may modify the HBM. In particular, worry may modify the impact of perceived risk of illness; a patient may perceive themselves to be at risk, but unless this is something that worries them they may not engage in a preventative behaviour. ${ }^{17}$ Furthermore, anticipated regret of illness if a health behaviour is not performed is also recognised as a predictor of intent. ${ }^{18}$

The objective of this study was to explore the sociodemographic factors, and the vaccine and vaccination-specific health-beliefs that are associated with SIIV intention among HSCT recipients, using a HBM modified with the additional emotional constructs given above (mHBM). A better understanding of such associations may allow development of targeted strategies that address issues specific to this unique and complex patient group, with the aim of increasing influenza vaccine uptake rates.
PARTICIPANTS AND METHODS

\section{Participants}

Patients were screened by HSCT nurse specialists for study eligibility during routine outpatient appointments between June and September 2016. Participants were recruited from three study sites to reduce geographical bias. Eligible patients were aged 16 years or over and recipients of autologous or allogeneic HSCT for any disease indication, with no absolute contraindication to receiving the SIIV during the next influenza season, and having not received the SIIV since transplant.

\section{Study questionnaire and HBM}

Participants completed a study-specific, 42-item, paperbased questionnaire. The questionnaire was completed anonymously and returned in sealed envelopes, so participants felt free to express their belief without influence from their healthcare team.

Questions scoped type of HSCT (autologous or allogeneic), disease indication, time from HSCT, pre-HSCT SIIV receipt and receipt of non-SIIV vaccines since HSCT. Sociodemographic questions established age, gender, ethnic background, educational attainment, relationship status and residential circumstances.

Intention to receive the SIIV during the 2016-2017 influenza season was assessed by two statements phrased in the affirmative (I intend to receive the influenza vaccine next winter) and negative (I will choose not to receive the influenza vaccine next winter). Participants' agreement with each statement was expressed on 5-point Likert scales ranging from strongly disagree to strongly agree. Twenty-four health belief statements were mapped to the mHBM with between 2 and 5 statements clustered around each construct (box 1). Statements pertaining to the cues to vaccination construct were phrased to explore perception of HSCT team and GP knowledge of SIIV in the context of HSCT. Participants' perceived impact of a recommendation to receive the SIIV from their HSCT team or GP was explored. Statements about preferred vaccination location and ease of access to services were also included. Again, participants' agreement with each statement was expressed on 5-point Likert scales ranging from strongly disagree to strongly agree.

\section{Statistical analysis}

Statistical analysis was performed with IBM SPSS V.24. For the dependent variable vaccination intention, participants' agreement scores were summed and dichotomised to a 'high-intent' group (intention score $>$ neutral value) and a 'low-intent' group (intention score $\leq$ to the neutral value).

Categorical patient characteristics and sociodemographic factors are reported as frequencies and percentages. Associations between these variables and SIIV intention was examined with Pearson's $\chi^{2}$ test, and Fisher's exact test when expected values were less than 5 .

Internal scale reliability for each cluster of mHBM construct statements was assessed using Cronbach's $\alpha$. 
Box 1 Health belief statements grouped by construct with associated Cronbach's $\alpha$ value

\section{Health belief model construct (Cronbach's $\alpha$ )}

1. Susceptibility to seasonal influenza $(\alpha=0.83)$

- Now I have had a stem cell transplant, I can catch seasonal influenza more easily than other people my age.

- Now I have had a stem cell transplant, I can catch seasonal influenza more easily than before my transplant.

2. Likelihood of catching seasonal influenza $(\alpha=0.91)$

- My chances of catching seasonal influenza next winter will be high if I do not receive the seasonal influenza vaccine.

- I am more likely than other people my age to catch seasonal influenza next winter if I do not receive the seasonal influenza vaccine.

- Now I have had a stem cell transplant, it is more likely that I will catch seasonal influenza next winter if I do not receive the seasonal influenza vaccine. 3. Severity of seasonal influenza infection $(\alpha=0.91)$

- If I do not receive the seasonal influenza vaccine and caught seasonal influenza next winter this would be a serious illness for me.

- If I do not receive the seasonal influenza vaccine and caught seasonal influenza next winter, this would have a negative impact on my recovery from my stem cell transplant.

- If I do not receive the seasonal influenza vaccine and caught seasonal influenza next winter, I would become more unwell than other people my age.

4. Barriers to vaccination $(\alpha=0.84)$

- I am worried about the side effects of the seasonal influenza vaccine.

- If I receive the seasonal influenza vaccine next winter, it may make me feel unwell with influenza or an influenza-like illness.

- If I receive the seasonal influenza vaccine next winter, I am more likely to experience side effects than other people my age.

- If I receive the seasonal influenza vaccine next winter, it may have a negative impact on my recovery from my stem cell transplant.

- Now I have had a stem cell transplant the seasonal influenza vaccine may not work as well for me as it does for other people my age.

5 . Benefits of vaccination $(\alpha=0.66)$

- If I receive the seasonal influenza vaccine next winter, it may help to prevent me from catching seasonal influenza.

- If I receive the seasonal influenza vaccine next winter, it may help to prevent me from passing seasonal influenza to other people around me.

- If I receive the seasonal influenza vaccine next winter, but still catch influenza, it may help to prevent me from becoming seriously unwell.

6. Cues to vaccination $(\alpha=0.76)$

- If my transplant team advised me to receive the seasonal influenza vaccine next winter, I would definitely have it.

- If my general practitioner (GP) advised me to receive the seasonal influenza vaccine next winter, I would definitely have it.

- My GP understands my condition enough to know if the seasonal influenza vaccine is right for me.

- My transplant team understand my condition enough to know if the seasonal influenza vaccine is right for me.

7. Worry $(\alpha=0.47)$

- If I receive the seasonal influenza vaccine next winter, I will worry less about catching seasonal influenza.

The thought of catching seasonal influenza next winter worries me.

8. Self-efficacy $(\alpha=0.29)$

- I have enough information and am able to decide whether the seasonal influenza vaccine is right for me.

- I would find it easy to attend my GP surgery next winter to receive the seasonal influenza vaccine.

9. Anticipated regret $(\alpha=0.15)$

- I would regret it if I decided not to receive the seasonal influenza vaccine next winter and became unwell with seasonal influenza.

I would regret it if I decided to receive the seasonal influenza vaccine next winter and became unwell with side effects.

A value of $>0.6$ was considered indicative of acceptable internal scale reliability. ${ }^{19}$ Scale reliability was acceptable for constructs 1-6 (box 1) and statement scores were summed to give total construct scores for each participant. Scale reliability was unacceptable for constructs 7-9 (box 1); therefore, statements were analysed individually. All construct scores were analysed as continuous scales, with 0 representing a neutral response (neither agree nor disagree). Mean agreement scores for low-intent and high-intent groups are presented with $95 \%$ CIs.

Participants' mean agreement scores for each mHBM construct were compared between SIIV intention groups using analysis of variance. Homogeneity of variances was confirmed with Levene's statistic. HSCT team and GP cue scores within low-intent and high-intent groups were compared with a paired sample t-test.

The impact of sociodemographic variables and health belief constructs on seasonal influenza vaccination intention was examined with hierarchical binary logistic regression. Variables and constructs that were statistically significant in univariate analysis were included as separate regression blocks. Statistically significant variables that improved the predictive value $(p<0.05$ for the regression block) were included in the final model.

The assumption of a linear relationship between each independent variable and log of the outcome variable was tested and confirmed using the Box-Tidwell procedure. ${ }^{20}$ Multicollinearity across all constructs was assessed. No variance inflation factor was greater than 10 , and the mean of values was acceptable at $1.92 .^{21}$

There were 10 missing data points from 6 participants across the study. These were all responses to mHBM statements from the high-intent group. Summed agreement scores were not calculated for that participant for the affected HBM construct only.

\section{Patient and public involvement}

The study questionnaire was developed with the involvement of volunteers from the Anthony Nolan patients and families panel. Using an initial draft questionnaire, 
think-aloud sessions were conducted to ensure that the questionnaire was clear, easy to understand, that interpretation of each question was as intended, and that answers were consistent with the question asked. Volunteers were also asked for their overall feedback on the study questionnaire. The revised questionnaire was then piloted with volunteer patients who were asked to complete the questionnaire, keeping note of the time taken and to highlight any questions that they had difficulty answering or otherwise found problematic. The questionnaires were all completed within 10 minutes and no participants reported difficulty or concerns about the questions. Results will be disseminated to study participants through their transplant teams, and made available to participants through open access publication.

\section{RESULTS}

\section{Patient characteristics}

Characteristics of 93 study participants are given in table $1.78 .5 \%$ were recipients of allogeneic HSCT and the most frequent disease indication was acute myeloid leukaemia $(28.0 \%)$. The majority $(68.6 \%)$ were within the first 6 months post-HSCT. $40.9 \%$ of participants had received the SIIV before HSCT, and $4.3 \%$ had received a non-influenza vaccine since HSCT. $52.7 \%$ of participants were male, and most $(84.9 \%)$ were of a white ethnic group.

\section{SIIV vaccination intention for 2016-2017 influenza season}

Seventy-one $(76.3 \%)$ participants expressed high SIIV intent, while 22 (23.7\%) expressed low SIIV intent.

\section{Sociodemographic and transplant variables}

There was a statistically significant difference in SIIV intention between age groups (table 1). Rate of high intent was greatest in the 35-54 age group at $91.7 \%$, and lowest at $53.3 \%$ in the $65+$ age group. There was no statistically significant difference in gender, ethnicity, educational background, living circumstance or relationship status between SIIV intention groups.

There was no difference in type of HSCT or disease indication between SIIV intention groups. $81.3 \%$ of participants answering within the first $0-6$ months post-HSCT had high intent, compared with $70 \%$ in those answering at $6-12$ months, and $55.6 \%$ among those answering at $>12$ months from HSCT, however, this finding was not statistically significant. To determine whether there was a difference in health beliefs between participants at different time points post-HSCT, mean agreement scores for all constructs were compared. There was no difference in mean agreement scores between participants at $0-6$ and 6-12 and >12 months post-HSCT. There was no association between SIIV intention and receipt of any non-influenza vaccine since HSCT. However, of those who had received the SIIV prior to HSCT $89.5 \%$ had high intent compared with $67.3 \%$ of those who had not.

\begin{tabular}{|c|c|c|c|}
\hline Characteristic, $n=93$ & n (\%) & $\begin{array}{l}\text { High SIIV } \\
\text { intent n (\%) }\end{array}$ & $P$ values \\
\hline \multicolumn{4}{|l|}{ Gender } \\
\hline Male & $49(52.7)$ & $40(81.6)$ & \\
\hline Female & $44(47.3)$ & $31(70.5)$ & 0.23 \\
\hline \multicolumn{4}{|l|}{ Age group } \\
\hline $16-34$ & $22(23.7)$ & 15 (68.2) & \\
\hline $35-54$ & $36(38.7)$ & $33(91.7)$ & \\
\hline $55-64$ & $20(21.5)$ & $15(75)$ & \\
\hline $65+$ & $15(16.1)$ & $8(53.5)$ & $0.02^{\star}$ \\
\hline \multicolumn{4}{|l|}{ HSCT type } \\
\hline Allogeneic & $73(78.5)$ & $59(80.8)$ & \\
\hline Autologous & $20(21.5)$ & $15(75)$ & 0.78 \\
\hline \multicolumn{4}{|l|}{ Disease indication } \\
\hline $\begin{array}{l}\text { Acute lymphoblastic } \\
\text { leukaemia }\end{array}$ & $11(11.8)$ & $8(72.7)$ & \\
\hline $\begin{array}{l}\text { Acute myeloid } \\
\text { leukaemia }\end{array}$ & $26(28.0)$ & $20(76.9)$ & \\
\hline Aplastic anaemia & $5(5.4)$ & $3(60)$ & \\
\hline $\begin{array}{l}\text { Chronic myeloid } \\
\text { leukaemia }\end{array}$ & $5(5.4)$ & $5(100)$ & \\
\hline Hodgkin lymphoma & $9(9.7)$ & $9(88.9)$ & \\
\hline $\begin{array}{l}\text { Myelodysplastic } \\
\text { syndrome }\end{array}$ & $5(5.4)$ & $3(60)$ & \\
\hline Myelofibrosis & $2(2.2)$ & $1(50)$ & \\
\hline Multiple myeloma & $22(23.7)$ & $17(77.3)$ & \\
\hline $\begin{array}{l}\text { Non-Hodgkin's } \\
\text { lymphoma }\end{array}$ & $8(8.6)$ & $6(75)$ & 0.79 \\
\hline \multicolumn{4}{|l|}{ Months from HSCT } \\
\hline $0-6$ & $64(68.8)$ & $52(81.3)$ & \\
\hline$>6-12$ & $20(21.5)$ & $14(70)$ & \\
\hline$>12$ & $9(9.7)$ & $5(55.6)$ & 0.18 \\
\hline \multicolumn{4}{|l|}{ SIIV before HSCT } \\
\hline Yes & $38(40.9)$ & $34(89.5)$ & \\
\hline No & $55(59.1)$ & 37 (67.3) & $0.01^{*}$ \\
\hline \multicolumn{4}{|c|}{$\begin{array}{l}\text { Any non-SIIV vaccine since } \\
\text { HSCT }\end{array}$} \\
\hline Yes & $4(4.3)$ & $4(100)$ & \\
\hline No & 89 (95.7) & $67(75.3)$ & 0.26 \\
\hline \multicolumn{4}{|l|}{ Ethnicity } \\
\hline White & $79(84.9)$ & $69(77.2)$ & \\
\hline Asian & $8(8.6)$ & $7(87.5)$ & \\
\hline Black & $3(3.2)$ & $2(66.7)$ & \\
\hline Mixed & $2(2.2)$ & $1(50)$ & \\
\hline Other & $1(1.1)$ & $0(0)$ & 0.32 \\
\hline \multicolumn{4}{|l|}{ Educational background } \\
\hline Higher education & $30(32.3)$ & $24(80)$ & \\
\hline Secondary education & $49(52.7)$ & $40(81.6)$ & \\
\hline Other & $3(3.2)$ & $2(66.7)$ & \\
\hline
\end{tabular}




\begin{tabular}{|c|c|c|c|}
\hline Characteristic, $n=93$ & n (\%) & $\begin{array}{l}\text { High SIIV } \\
\text { intent n (\%) }\end{array}$ & $P$ values \\
\hline Prefer not to answer & $11(11.8)$ & $5(45.5)$ & 0.07 \\
\hline \multicolumn{4}{|l|}{ Living circumstances } \\
\hline Renting & $25(26.9)$ & $33(76)$ & \\
\hline Home owner & $54(58.1)$ & 43 (79.6) & \\
\hline Other & $10(10.8)$ & $7(70)$ & \\
\hline Prefer not to answer & $4(4.7)$ & $2(50)$ & 0.56 \\
\hline \multicolumn{4}{|l|}{ Relationship status } \\
\hline Single & $23(24.7)$ & 18 (78.3) & \\
\hline Married/cohabiting & $56(60.2)$ & $45(80.4)$ & \\
\hline Divorced/separated & $10(10.8)$ & $5(50)$ & \\
\hline Prefer not to answer & $4(4.4)$ & $3(75)$ & 0.22 \\
\hline
\end{tabular}

*Statistically significant $(p<0.05)$.

HSCT, haematopoietic stem cell transplant; SIIV, seasonal inactivated influenza vaccine.

\section{HBM constructs}

In univariate analysis, comparing mean construct agreement scores between SIIV intention groups, participants in the high-intent group perceived greater susceptibility to influenza, a greater likelihood of contracting influenza and perceived influenza to be a more severe illness (table 2). They also perceived greater potential benefit from vaccination, and fewer barriers to vaccination. Although the two groups expressed similar levels of worry about catching influenza, participants in the high-intent group felt they would worry less about catching influenza if vaccinated compared with the low-intent group. They also expressed greater concern about anticipated regret if they caught influenza having not been vaccinated. Level of anticipated regret of experiencing side effects if vaccinated was similarly low across the two groups. Participants in the high-intent group felt more strongly that they had enough information to make decisions about vaccination and that it would be easy to attend their general practice surgery for vaccination.

A multivariate regression model (table 3) was statistically significant when compared with a constant only model indicating that this set of variables and constructs distinguishes reliably between HSCT recipients who express low and high SIIV intent. There was a moderately strong relationship with $74.7 \%$ (Nagelkerke $\mathrm{R}^{2}$ ) of variation in vaccination intention explained by the overall model. GP and HSCT team cues to vaccination, self-efficacy and anticipated regret constructs did not significantly improve predictive value and so were not included in the final model. Age and pre-HSCT SIIV vaccination receipt remained independent predictors of SIIV intention, with those aged $>65$ and those who had not received SIIV before HSCT more likely to be in the low-intent group. A greater perceived benefit of vaccination was the

\begin{tabular}{|c|c|c|c|}
\hline Health belief model construct & Low SIIV intent $(\mathrm{n}=22)$ & High SIIV intent $(n=71)$ & P values \\
\hline 1. Susceptibility to seasonal influenza & $0.05(-0.70$ to 0.70$)$ & 2.09 (1.75 to 4.39$)$ & $<0.001$ \\
\hline 2. Likelihood of catching seasonal influenza & $-0.45(-1.39$ to 0.40$)$ & $2.58(2.00 \text { to } 3.18)^{\star}$ & $<0.001$ \\
\hline 3. Severity of seasonal influenza infection & $0.77(-0.17$ to 1.72$)$ & $2.65(2.09 \text { to } 3.23)^{*}$ & 0.002 \\
\hline 4. Barriers to vaccination & $1.27(0.11$ to 2.44$)$ & $-1.55(-2.34$ to -0.80$) \dagger$ & 0.001 \\
\hline 5. Benefits of vaccination & $-0.05(0.00$ to 1.78$)$ & $2.56(2.13$ to 3.00$)$ & $<0.001$ \\
\hline \multicolumn{4}{|l|}{ 6. Cues to vaccination } \\
\hline HSCT team understands my condition & 1.14 (0.55 to 1.32$)$ & 1.63 (1.52 to 1.75$)$ & $<0.001$ \\
\hline GP understands my condition & $-0.32(0.83$ to 0.13$)$ & $0.59(0.55$ to 0.83$) \ddagger$ & $<0.001$ \\
\hline \multicolumn{4}{|l|}{ 7. Worry } \\
\hline About catching influenza & $0.14(-0.43$ to 0.71$)$ & $0.39(0.17$ to -0.63$)$ & 0.34 \\
\hline Less about catching influenza if vaccinated & $-0.23(0.60$ to 0.07$)$ & $0.80(0.61$ to 1.00$)$ & $<0.001$ \\
\hline \multicolumn{4}{|l|}{ 8. Self-efficacy } \\
\hline $\begin{array}{l}\text { Have enough information to decide about } \\
\text { vaccination }\end{array}$ & $0.14(-0.32$ to 0.58$)$ & 0.81 (0.61 to 1.00$)$ & 0.007 \\
\hline Would find it easy to attend GP for vaccination & $0.32(-0.12$ to 1.72$)$ & 1.10 (1.89 to 2.00$)$ & $<0.001$ \\
\hline \multicolumn{4}{|c|}{ 9. Anticipated regret } \\
\hline Of catching influenza if not vaccinated & $0.27(-0.21$ to 0.74$)$ & 1.35 (1.18 to 1.52$)$ & $<0.001$ \\
\hline Of side effects if vaccinated & $-0.09(-0.15$ to 0.37$)$ & $0.13(-0.12$ to 0.39$)$ & 0.4 \\
\hline
\end{tabular}

${ }^{*} \mathrm{n}=69$.

$\dagger \mathrm{n}=68$.

$\ddagger \mathrm{n}=70$.

GP, general practitioner; HSCT, haematopoietic stem cell transplant; SIIV , seasonal inactivated influenza vaccine. 
Table 3 Multivariate logistic regression model predicting odds of high SIIV intent

\begin{tabular}{|c|c|c|}
\hline Variable & $\begin{array}{l}\text { OR of high SIIV } \\
\text { intent }(95 \% \mathrm{CI})\end{array}$ & $P$ values \\
\hline Age $>65$ & 0.02 (0.01 to 0.57$)$ & $0.02^{*}$ \\
\hline No SIIV before HSCT & 0.04 (0.02 to 0.56$)$ & $0.02^{*}$ \\
\hline Benefits of vaccination & 2.96 (1.29 to 6.81$)$ & $0.01^{*}$ \\
\hline $\begin{array}{l}\text { Susceptibility to seasonal } \\
\text { influenza }\end{array}$ & 0.96 (0.33 to 2.78$)$ & 0.64 \\
\hline $\begin{array}{l}\text { Likelihood of catching } \\
\text { seasonal influenza }\end{array}$ & $1.68(0.86$ to 3.26$)$ & 0.13 \\
\hline $\begin{array}{l}\text { Severity of seasonal } \\
\text { influenza infection }\end{array}$ & $0.69(0.39$ to 1.21$)$ & 0.20 \\
\hline Barriers to vaccination & 0.69 (0.57 to 0.99$)$ & 0.05 \\
\hline $\begin{array}{l}\text { Worry less about catching } \\
\text { seasonal influenza if } \\
\text { vaccinated }\end{array}$ & 4.99 (1.01 to 24.77$)$ & 0.05 \\
\hline
\end{tabular}

Overall model was statistically significant compared with a constant only model $(p<0.001)$.

*Statistically significant independent predictor $(p<0.05)$. HSCT, haematopoietic stem cell transplant; SIIV, seasonal inactivated influenza vaccine.

strongest predictor of being in the high-intent group. Although the constructs susceptibility to influenza, likelihood of contracting influenza, severity of influenza infection, barriers to vaccination and worry about catching influenza improved the predictive value of the overall multivariate model, they did not independently predict vaccination intention.

\section{Cues to vaccination and preferred vaccination location}

Considering their HSCT team and GPs, both high-intent and low-intent groups agreed more strongly with statements that their HSCT team understands their condition enough to know if the influenza vaccine is right for them. Patients were also asked how much they agreed with the statement that they would definitely have the vaccine if their GP or HSCT team recommended it. Agreement scores were dichotomised to low agreement ( $\leq$ neutral value) and high agreement (>neutralvalue). Of those 22 patients with low intent, $90 \%$ agreed that they would receive the vaccine if their HSCT team recommended it, and only $22.7 \%$ if their GP recommended it, compared with $98.6 \%$ and $90.0 \%$, respectively, in the high-intent group.

Participant responses to the statement I would prefer to have the seasonal influenza vaccine next winter at my transplant centre instead of my GP surgery were categorised into prefers HSCT centre, prefers GP surgery or no preference. Of the low-intent group, over half $(54.5 \%)$ favoured vaccination at their HSCT centre, with only a minority $(4.5 \%)$ favouring vaccination at their GP surgery. Of those with high intent, $43.7 \%$ favoured vaccination at their HSCT programme, compared with $29.6 \%$ at their GP surgery although these findings did not reach statistical significance $(\mathrm{p}=0.05)$.

\section{DISCUSSION}

This is the first study to explore sociodemographic factors and psychological determinants of SIIV intention among HSCT recipients. Approximately, a quarter of participants expressed low SIIV intent which is in keeping with previously reported SIIV uptake rates of $60 \%-70 \% .{ }^{10} 11$ Participants' SIIV uptake during the 2016-2017 UK influenza season was not evaluated, and uptake in this cohort may not be equivalent to intent rates reported here.

Constructs of a mHBM were significant determinants of SIIV intention. Strategies tailored to a population and their specific concerns are the most effective at improving knowledge and changing attitudes towards vaccination, and increasing vaccine uptake. ${ }^{22}$ Based on our findings, the mHBM may provide a useful framework for structuring strategies to address low SIIV intent in the HSCT population. Exploring HSCT recipients' increased risk of influenza, both in terms of susceptibility and severity, discussing the potential benefits of vaccination, and exploring concerns around side effects may help to promote vaccine intent and uptake.

A strong association between past vaccination behaviours and future vaccination intent has been reported. ${ }^{23}$ Previous influenza vaccination has been associated with high-intent or uptake in all at-risk groups ${ }^{24} 25$ and patients with cancer ${ }^{26}$ and our findings accord with this. It may therefore be helpful to explore recipients pre-HSCT SIIV behaviour and discussion rationale for refusal where appropriate.

It was reassuring to find that none of gender, ethnicity, educational background, living circumstances or relationship status were associated with vaccine hesitancy in this study. However, vaccination intention did vary with age. High intent was greatest at $91.7 \%$ in the $35-53$ age bracket, but of concern, fell in those over $65 \%-53.5 \%$, which is below the 2015-2016 uptake rate of $71 \%$ in the equivalent UK general population age group. ${ }^{27}$ Older age has been reported as a barrier to vaccination in a cohort of oncology patients, including some with haematological malignancy. ${ }^{26}$ However, a French study of patients with secondary immunodeficiency, including haematological disorders, reported higher vaccination rates in those aged over 65 compared with younger patients. ${ }^{28}$ In a UK study, older age was found to be a predictor of uptake of the 2009 pandemic influenza A vaccine among high-risk adults. ${ }^{29}$ A meta-analysis of international studies found inconsistent association between age and vaccination intent and uptake in the general public, older patients and those with chronic disease. ${ }^{23}$ It is not apparent from these studies why age impacts on intent, and there are likely to be a range of social, psychological, financial and healthcare access issues specific to each study population. Our findings highlight a specific age group in whom intent is low and 
may benefit from targeted intervention. Further evaluation of this finding and exploration of underlying determinants is warranted.

High SIIV intent was greatest in those recipients within the first 0-6 months post-HSCT $(81.3 \%)$ and lowest at more than 12 months (55.6\%) although this finding was not statistically significant. Longer time from HSCT may be associated with a change in perceived risk of infection, or concern about vaccine side effects or efficacy; however, we did not detect any statistically significant difference in health beliefs at $0-6,6-12$ and $>12$ months from HSCT. This finding suggests there is a need for reinforcement of SIIV intent from healthcare professionals throughout and beyond the first-year post-HSCT.

In both vaccine intention groups, patients expressed greater confidence in their HSCT team than their GP, with respect to understanding of whether the influenza vaccine is right for them. Fewer patients felt that a recommendation from their GP would prompt them to receive the SIIV compared with if their HSCT team made the recommendation. This was most marked in the low-intent group. These findings suggest that cues from the HSCT team are important in promoting vaccination among HSCT recipients, and particularly for those with low intent. Cues from healthcare providers are considered a key factor in promoting vaccination ${ }^{23}$ and a study of Israeli patients with cancer identified recommendation from an oncologist as a significant predictor of vaccine uptake. ${ }^{26}$ Our findings accord with this, and suggest that HSCT recipients value the advice of their specialist team. This highlights the importance of HSCT specialists engaging in discussion with patients about influenza vaccination. Preference for vaccination at an HSCT centre rather than GP surgery was similar at $43.7 \%$ and $54.5 \%$ in low-intent and high-intent groups, respectively. In the high-intent group, more patients expressed a preference for vaccination at their GP surgery than in the low-intent group. For approximately $50 \%$ of those HSCT recipients with both low and high intent, access to an SIIV service at HSCT centres may facilitate vaccination uptake.

None of the transplant variables assessed were associated with SIIV intention. Current influenza vaccination guidelines are standardised for all HSCT recipients as evidence is insufficient to recommend modification according to donor type, stem cell source or conditioning. ${ }^{730}$ Influenza infections are reported to occur with higher frequency in allogeneic compared with autologous HSCT recipients ${ }^{31} 32$ and may have a higher associated morbidity and mortality ${ }^{33}$ although this latter finding has not been consistently reported. ${ }^{4}$ There was no difference in vaccination intention between autologous and allogeneic HSCT recipients. This suggests the unique aspects of allogeneic HSCT, principally GvHD and the need for immunosuppressive therapy, do not contribute to increased influenza vaccination intention in this group compared with autoHSCT recipients.

\section{STRENGTH AND WEAKNESSES OF THE STUDY}

Our study was developed from an established theoretical framework for exploring health beliefs. Think-aloud sessions and a pilot exercise ensured that the questionnaire was easy to understand and acceptable to participants. By completing the questionnaire anonymously, participants were encouraged to respond according to their own beliefs without influence by their healthcare team. By recruiting from three study sites, we sought to capture the beliefs of participants with different experiences of post-HSCT care, reduce the impact of geographical bias and render our results more generalisable to the UK HSCT population. The study did not include a qualitative component and there may be additional determinants of influenza vaccine intention not captured here. Data on non-responders were not captured and therefore we cannot exclude a participation bias. The small absolute number of participants expressing low SIIV intent in our study may bias our data.

\section{CONCLUSION}

Our data indicate that the constructs of a mHBM are important determinants of SIIV intention in the HSCT recipient population. These constructs may be used to develop interventions addressing low SIIV intent, for example, SIIV uptake among HSCT recipients may be promoted by public health authorities and patient support groups with messages adapted from our findings. Future prospective studies to investigate the efficacy of such intervention are warranted. HSCT recipients strongly value the expertise and recommendation of their transplant team, and we would encourage practitioners to discuss SIIV intention with all patients as a routine and important aspect of post-transplant care. Furthermore, those aged over 65, and those who had not received the SIIV prior to HSCT were particularly likely to have low intent and may be target groups. Local provision of vaccination services at HSCT centres may serve as an additional promoter for a proportion of patients and this would require allocation of resources from health commissioners.

\section{Author affiliations \\ ${ }^{1}$ Anthony Nolan Research Institute, Anthony Nolan Trust, London, UK \\ ${ }^{2}$ Research Department of Behavioural Science and Health, University College London, London, UK \\ ${ }^{3}$ Department of Infection and Tropical Medicine, Sheffield Teaching Hospitals NHS Foundation Trust, Sheffield, UK \\ ${ }^{4}$ Department of Haemato-Oncology, Royal Marsden NHS Foundation Trust, London, UK \\ ${ }^{5}$ Department of Haematology, St George's NHS Foundation Trust, London, UK ${ }^{6}$ Northern Centre for Cancer Care, Freeman Hospital, Newcastle upon Tyne, UK ${ }^{7}$ Department of Clinical Haematology, University College London Hospitals NHS Foundation Trust, London, UK \\ ${ }^{8}$ Department of Haematology, Sheffield Teaching Hospitals NHS Foundation Trust, London, UK}

Acknowledgements The authors would like to thank the volunteers who contributed to the development of the study questionnaire. The authors also wish to thank the stem cell transplant recipients who participated in the study. 
Contributors PDEM, ASF, TIdS, KP, AM and JAS contributed substantially to the design, analysis and interpretation of data. HL, CA, MM, MK, EH and SP contributed substantially to the acquisition of data. All authors contributed to drafting the work and/or revising it critically for intellectual content. All authors gave final approval of the version to be published.

Funding This work was supported by the Anthony Nolan Research Institute (No grant number). ASF is funded by Cancer Research UKC49896/A17429.

Competing interests None declared.

Patient consent Not required.

Ethics approval The study was approved by the Health Research Authority National Research Ethics Committee (Reference 16/WM/0144).

Provenance and peer review Not commissioned; externally peer reviewed.

Data sharing statement № additional data are available.

Open access This is an open access article distributed in accordance with the Creative Commons Attribution Non Commercial (CC BY-NC 4.0) license, which permits others to distribute, remix, adapt, build upon this work non-commercially, and license their derivative works on different terms, provided the original work is properly cited, appropriate credit is given, any changes made indicated, and the use is non-commercial. See: http://creativecommons.org/licenses/by-nc/4.0/.

\section{REFERENCES}

1. Dertschnig S, Hauri-Hohl MM, Vollmer M, et al. Impaired thymic expression of tissue-restricted antigens licenses the de novo generation of autoreactive CD4+ T cells in acute GVHD. Blood 2015;125:2720-3.

2. Krenger W, Rossi S, Piali L, et al. Thymic atrophy in murine acute graft-versus-host disease is effected by impaired cell cycle progression of host pro-T and pre-T cells. Blood 2000;96:347-54.

3. Cuthbert RJ, Iqbal A, Gates A, et al. Functional hyposplenism following allogeneic bone marrow transplantation. J Clin Pathol 1995;48:257-9.

4. Nichols WG, Guthrie KA, Corey L, et al. Influenza infections after hematopoietic stem cell transplantation: risk factors, mortality, and the effect of antiviral therapy. Clin Infect Dis 2004;39:1300-6.

5. Whimbey E, Elting LS, Couch RB, et al. Influenza A virus infections among hospitalized adult bone marrow transplant recipients. Bone Marrow Transplant 1994;13:437-40.

6. Shah DP, Ghantoji SS, Mulanovich VE, et al. Management of respiratory viral infections in hematopoietic cell transplant recipients. 2012;2:203-18.

7. Rubin LG, Levin MJ, Ljungman P, et al. IDSA clinical practice guideline for vaccination of the immunocompromised host. Clin Infect Dis 2013;2014:1-57.

8. Miller PDE, de Silva TI, Skinner R, et al. Routine vaccination practice after adult and paediatric allogeneic haematopoietic stem cell transplant: a survey of UK NHS programmes. Bone Marrow Transplant 2017;52:775-7.

9. Tomblyn M, Chiller T, Einsele H, et al. Guidelines for preventing infectious complications among hematopoietic cell transplantation recipients: a global perspective. Biol Blood Marrow Transplant 2009;15:1143-238.

10. Leonard $\mathrm{H}$, Anthias $\mathrm{C}$. Improving the re-vaccination programme for patients post allograft. Bone Marrow Transplant 2015;50:216-7.

11. Meiring J, de Silva TI, Snowden JA. A study of adherence to a vaccination schedule following adult allogeneic haematopoietic stem cell transplants in UK transplant centre. Bone Marrow Transplant 2015;50:s203-4.

12. Ambati A, Boas LS, Ljungman P, et al. Evaluation of pretransplant influenza vaccination in hematopoietic SCT: a randomized prospective study. Bone Marrow Transplant 2015;50:858-64.
13. Machado CM, Cardoso MR, da Rocha IF, et al. The benefit of influenza vaccination after bone marrow transplantation. Bone Marrow Transplant 2005;36:897-900.

14. Ariza-Heredia EJ, Gulbis AM, Stolar KR, et al. Vaccination guidelines after hematopoietic stem cell transplantation: practitioners' knowledge, attitudes, and gap between guidelines and clinical practice. Transpl Infect Dis 2014;16:878-86.

15. Rosenstock IM. Why people use health services. Milbank Mem Fund Q 1966;44:94-8.

16. Brewer NT, Chapman GB, Gibbons FX, et al. Meta-analysis of the relationship between risk perception and health behavior: the example of vaccination. Health Psychol 2007;26:136-45.

17. Chapman GB, Coups EJ. Emotions and preventive health behavior: worry, regret, and influenza vaccination. Health Psychol 2006;25:82-90.

18. Abraham $C$, Sheeran $P$. Acting on intentions: the role of anticipated regret. Br J Soc Psychol 2003;42:495-511.

19. Panayides P. Coefficient Alpha: Interpret With Caution. Eur J Psychol 2013;9:687-96.

20. Gep B, Tidwell PW. Transformation of the Independent Variables. Technometrics 1962;4:531-50.

21. Field A. Discovering Statistics Using IBM SPSS Statistics. Fourth. Sage 2014.

22. Jarrett $C$, Wilson $R, O^{\prime} L e a r y ~ M$, et al. Strategies for addressing vaccine hesitancy - A systematic review. Vaccine 2015;33:4180-90.

23. Schmid P, Rauber D, Betsch C, et al. Barriers of Influenza Vaccination Intention and Behavior - A Systematic Review of Influenza Vaccine Hesitancy, 2005 - 2016. PLoS One 2017;12:e0170550-46.

24. Nagata JM, Hernández-Ramos I, Kurup AS, et al. Social determinants of health and seasonal influenza vaccination in adults $\geq 65$ years: a systematic review of qualitative and quantitative data. BMC Public Health 2013;13:1-25.

25. Yeung MPS, Fly L, Coker R. Factors associated with the uptake of seasonal influenza vaccination in adults: a systematic review. $J$ Public Health 2016;38:746-53.

26. Vinograd I, Baslo R, Eliakim-Raz N, et al. Factors associated with influenza vaccination among adult cancer patients: a case-control study. Clin Microbiol Infect 2014;20:899-905.

27. NHS England. The National Flu Immunisation Programme 2016/2017. 2016. https://www.gov.uk/government/uploads/system/uploads/ attachment_data/file/529954/Annual_flu_letter_2016_2017.pdf (accessed 22 Feb 2017).

28. Loubet $\mathrm{P}$, Kernéis $\mathrm{S}$, Groh $\mathrm{M}$, et al. Attitude, knowledge and factors associated with influenza and pneumococcal vaccine uptake in a large cohort of patients with secondary immune deficiency. Vaccine 2015;33:3703-8.

29. Myers LB, Goodwin R. Using a theoretical framework to determine adults' intention to vaccinate against pandemic swine flu in priority groups in the UK. Public Health 2012;126:S53-S56.

30. Tomblyn M, Chiller T, Einsele H, et al. Guidelines for preventing infectious complications among hematopoietic cell transplant recipients: a global perspective. Preface. Bone Marrow Transplant 2009;44:1143-238.

31. Hassan IA, Chopra R, Swindell R, et al. Respiratory viral infections after bone marrow/peripheral stem-cell transplantation: the Christie hospital experience. Bone Marrow Transplant 2003;32:73-7.

32. Ljungman $P$, Ward KN, Crooks BNA, et al. Respiratory virus infections after stem cell transplantation: a prospective study from the Infectious Diseases Working Party of the European Group for Blood and Marrow Transplantation. Bone Marrow Transplant 2001;28:479-84.

33. Martino R, Porras RP, Rabella N, et al. Prospective study of the incidence, clinical features, and outcome of symptomatic upper and lower respiratory tract infections by respiratory viruses in adult recipients of hematopoietic stem cell transplants for hematologic malignancies. Biol Blood Marrow Transplant 2005;11:781-96. 